\title{
Los desafíos de la retroalimentación en la escritura. Estudio de caso en la enseñanza del español en secundaria en México
}

\section{Challenges of providing feedback on writing. A case study in language teaching in middle school education in Mexico}

DOI: https://doi.org/10.32870/dse.v0i23.782

\author{
Paloma Prado Robledo* \\ María Guadalupe Pérez Martínez**
}

\begin{abstract}
Resumen
La retroalimentación es una herramienta poderosa para promover los aprendizajes de los estudiantes, sin embargo, es compleja y sus características comúnmente no permiten que sea efectiva. En la escritura, la retroalimentación es fundamental porque permite al escritor saber en qué medida ha logrado comunicar lo que buscaba. Uno de los medios para proveer retroalimentación a las producciones escritas consiste en registrarla en los mismos textos. En este artículo se caracterizan las prácticas de retroalimentación de una docente de Español a los textos escritos de sus alumnos y se analiza su potencial para promover el aprendizaje. La investigación se diseñó como un estudio de casos empleando un acercamiento cualitativo; las técnicas de obtención de información fueron entrevistas semiestructuradas y análisis de tareas. Los resultados muestran que se utilizan tres recursos para proveer retroalimentación: asignación de calificaciones, comentarios escritos y marcas gráficas. Estos recursos están presentes en la mayoría de los trabajos escritos de los alumnos, pero el análisis de sus características mostró un potencial limitado para promover la mejora del aprendizaje de los estudiantes. Se discuten las implicaciones de los hallazgos con respecto a la formación docente, el diseño curricular y las investigaciones futuras en el campo.
\end{abstract}

Palabras clave: retroalimentación - enseñanza de la escritura - evaluación del estudiante - educación básica - práctica pedagógica.

\section{Abstract}

Feedback is considered a powerful tool to promote student learning, but it is complex and its characteristics usually do not often allow it to be effectiveness. In writing, feedback is essential because it allows the writer to know to what extent the communicative purpose has been achieved. Feedback on writing

\footnotetext{
* Maestra en Investigación Educativa. Investigadora independiente. Líneas de investigación: evaluación educativa, estudios de prácticas docentes, enseñanza y evaluación de la lengua, enseñanza y evaluación de las ciencias. México. pradopaloma@hotmail.com

** Doctora en Ciencia Política. Líneas de investigación: evaluación educativa y estudios de prácticas docentes. CONACyT-Universidad Autónoma de Aguascalientes. México. maria.perez@edu.uaa.mx

+ Se agradece a CONACYT por la beca otorgada para la realización de esta investigación, como parte de los estudios de posgrado de la primera autora.
} 
is frequently provided through comments within the same texts. This paper is aimed at characterizing the feedback provided to the written work of middle school students by a Mexican language teacher, and analyzing its potential to promote students' learning. Our research design was a case study, through a qualitative approach; data was collected through semi-structured interviews and artifacts. Our results show that assigning grades, writting comments, and making graphic marks were the main resources for providing feedback. These resources were present in most of the students' written works, but the analysis of their characteristics evidenced their limited potential to promote the improvement of student learning. Implications of the findings with respect to teacher training, curriculum design, and future research in the field are discussed.

Keywords: feedback - writing instruction - student evaluation - basic education - teaching practices.

\section{Introducción}

La escritura tiene un lugar privilegiado en la vida de los seres humanos, pues fija la lengua, objetiva el pensamiento y hace perdurar los registros del habla, por lo que se constituye como un "[...] vehículo intelectual, económico-administrativo, político y socio-cultural, a la hora de transmitir, fijar, organizar y gestionar multitud de asuntos [...]" (Riesco, 2002: 4).

En la construcción de conocimientos, la escritura también desempeña un papel fundamental, dado que es una "[...] herramienta intelectual que interviene no sólo en la expresión del conocimiento sino ante todo en la construcción de los saberes" (Lerner, Larramendy y Benchimol, 2010: 42); así, es un instrumento esencial para el aprendizaje y una pieza importante para el logro de una educación de calidad (UNESCO, 2015).

Si bien la relevancia de la escritura es incuestionable tanto en el contexto escolar como fuera de este, también es un hecho que su enseñanza y aprendizaje aún traen consigo múltiples dificultades a docentes y estudiantes, pues involucra los saberes relacionados con los géneros, estructuras y propiedades textuales, así como las diferentes habilidades y procedimientos vinculados con el proceso de composición escrita, es decir, fundamentalmente la enseñanza de la escritura implica enseñar a los alumnos a identificar diferentes situaciones comunicativas y las características que las distinguen, de tal manera que puedan ajustar sus producciones en función de ellas (Castelló, 2002).

En la literatura se reconoce que la evaluación de los aprendizajes es un elemento clave en el proceso de enseñanza y aprendizaje de la escritura, ya que permite a los estudiantes obtener información acerca del logro del propósito comunicativo de su escritura y contrastar su desempeño actual con el deseable, lo que les da la posibilidad de ajustar sus acciones y de autorregular su proceso de escritura (Castelló, 2002).

Este artículo tiene como propósito caracterizar las prácticas de retroalimentación de una docente de Español a las producciones escritas de sus alumnos, así como analizar el potencial

Diáloqos sobre Educación año 12 | número 23 | julio-diciembre 2021 | ISSN 2007-2171 
de dichas prácticas para promover su aprendizaje. La investigación se diseñó como un estudio de caso empleando una perspectiva cualitativa, y el análisis fue guiado por las siguientes preguntas: a) ¿qué recursos se utilizaron para dar retroalimentación a los alumnos en sus trabajos escritos?; b) ¿cómo interpretan los estudiantes la retroalimentación que se proporcionó a sus trabajos escritos?; y c) ¿qué correspondencia guarda la retroalimentación brindada con los criterios de retroalimentación efectiva derivados de la literatura?

El artículo se estructura en cinco apartados. Los dos primeros presentan la revisión de literatura sobre la retroalimentación en general, y la retroalimentación de la escritura en específico. En el tercero, se describe la metodología empleada para cumplir el propósito de este estudio. En el cuarto se reportan los resultados, en correspondencia con las preguntas de investigación. Y en el último apartado se discuten las implicaciones de los resultados con respecto a la formación docente, el diseño curricular y las investigaciones futuras en el campo.

\section{La retroalimentación: una herramienta para promover el aprendizaje de los alumnos}

La evaluación de los aprendizajes es una parte esencial del trabajo en el aula. Es un proceso centrado en la recolección, evaluación y uso de evidencias sobre el aprendizaje de los alumnos (Ravela et al., 2017); en este proceso participan tanto los docentes como los estudiantes (Brookhart, McMillan, 2020: 5). La evaluación de aprendizajes en las aulas puede tener diferentes propósitos, entre los que se encuentran el seguimiento al progreso de los estudiantes, la asignación de calificaciones, la provisión de retroalimentación; además, puede incluir tanto mediciones cuantitativas del aprendizaje como expresiones cualitativas sobre el pensamiento de los estudiantes. Los propósitos de la evaluación de aprendizajes en el aula, por lo general son clasificados en dos grandes tipos: formativos y sumativos. La evaluación adquiere un carácter formativo cuando las evidencias obtenidas se utilizan con el fin de mejorar el aprendizaje de los alumnos (Black, Wiliam, 2010); y es sumativa cuando se busca emitir un juicio sobre el dominio logrado por los estudiantes en un periodo de tiempo o unidad de enseñanza específico (Chappuis et al., 2014). Una característica específica de la evaluación en el aula es que sus propósitos son establecidos por el docente y es él quien regula la recolección, evaluación y uso de las evidencias.

Para que la evaluación pueda incidir de manera positiva en el desempeño de los educandos, es indispensable que se base en: objetivos de aprendizaje claramente definidos; una comprensión profunda de los propósitos con que se realiza la evaluación; un uso adecuado de diversos métodos o estrategias; y una comunicación efectiva (Chappuis et al., 2014). La comunicación, para ser efectiva, debe ser oportuna e incluir tanto los resultados de evaluaciones formativas como sumativas. La comunicación de los resultados de evaluaciones formativas provee retroalimentación descriptiva para la mejora de los aprendizajes de los alumnos; la comunicación de los resultados de evaluaciones sumativas permite conocer el grado de suficiencia de los apren- 
dizajes logrados por los estudiantes (Chappuis et al., 2014: 8) y, en ocasiones, estos dos tipos de comunicación se traslapan.

La retroalimentación ha sido definida, principalmente, como el proceso de brindar a los estudiantes información acerca de su nivel de logro actual con respecto a los objetivos de aprendizaje que deben alcanzar, y proporcionarles pistas que los ayuden a reducir la brecha entre su desempeño real y el deseable (Black, Wiliam, 1998; Bruno, Santos, 2010; Hattie, Timperley, 2007; Shute, 2008; Wiggins, 1998). En la última década, a la definición de retroalimentación se ha añadido que la información debe ser recibida y usada por los alumnos, transformando este constructo de una perspectiva unidireccional, donde el docente proporciona información al estudiante, a una bidireccional, donde la información llega al estudiante, la procesa y responde a ella con acciones que permitan clarificar las metas de aprendizaje y lo que deberán hacer posteriormente para alcanzarlas (Brookhart, 2017; Brooks et al., 2019; Lipnevich, Smith, 2009; Ruiz-Primo, Brookhart, 2018).

De acuerdo con lo anterior, la retroalimentación tiene que ver con tres dimensiones: la clarificación de las expectativas de aprendizaje, denominada Feed Up; el estado que guarda el aprendizaje alcanzado por los alumnos con respecto al esperado, denominada Feed Back; y las acciones que se deberán implementar para alcanzar los aprendizajes esperados, conocida como Feed Forward (Brooks et al., 2019; Hattie, Timperley, 2007). Además, la retroalimentación puede tener diferentes componentes: comentarios escritos u orales, de naturaleza descriptiva sobre la tarea, el proceso para realizarla o la autorregulación del aprendizaje (Brooks et al., 2019); comentarios escritos u orales sobre la persona, de naturaleza afectiva como elogios o desaprobaciones (Brookhart, 2017; Lipnevich, Smith, 2009); y calificaciones, juicios evaluativos sobre el desempeño de los estudiantes (Brookhart, 2017; Lipnevich, Smith, 2009).

Si bien es cierto que la retroalimentación es un elemento esencial de la evaluación formativa, puesto que permite ampliar el entendimiento de los estudiantes y señalar los próximos pasos en su trayectoria de aprendizaje para lograr los aprendizajes esperados con respecto a los que mostró en un momento específico (Timperley, 2013; Black et al., 2003), en diversos estudios se ha encontrado que no siempre cumple con su objetivo, pues la retroalimentación se brinda comúnmente en las aulas a través de calificaciones, elogios o desaprobaciones (Timperley, 2013: 404). En los metanálisis realizados por Hattie en 1999 (en Hattie, Timperley, 2007), que abarcaron 1,800 estudios con más de 100 factores que inciden en el aprendizaje de los estudiantes, se encontró que la retroalimentación tiene un efecto mayor en el desempeño de los alumnos que factores como la condición socioeconómica, la realización de tareas, la reducción del tamaño de la clase, entre otros. No obstante, también constató que no todas las prácticas de retroalimentación tienen el mismo impacto, dado que aquellas que se enfocaron en dar alabanzas, castigos o recompensas mostraron ser menos efectivas que las relacionadas con los objetivos de aprendizajes o las que brindaron pistas a los estudiantes. De hecho, se ha afirmado 
que algunos tipos de retroalimentación pueden afectar negativamente el desempeño de los estudiantes (Timperley, 2013), por ejemplo, cuando se asigna una calificación sin comentarios (Lipnevich, Smith, 2009).

En América Latina y México, algunas investigaciones han reportado que la comunicación escrita de resultados de aprendizaje que hacen los docentes no ofrece suficiente información a los estudiantes. Picaroni (2009) estudió las concepciones de los profesores acerca de sus propias prácticas de evaluación en ocho países latinoamericanos (Argentina, El Salvador, México, Colombia, Costa Rica, Guatemala, Perú y Uruguay) e identificó que pocos docentes proporcionan a los estudiantes información acerca de sus logros y limitaciones, así como estrategias para superarlas; la mayoría asigna calificaciones que solo dan indicios de que algo "está bien" o "está mal" en el desempeño de los alumnos. García et al. (2011), a partir de una investigación llevada a cabo en México, cuyo objetivo fue realizar una descripción de las opiniones y prácticas de los docentes de primaria con respecto a la evaluación de los aprendizajes, encontraron que una gran parte de los profesores (70\%) retroalimenta las tareas y trabajos de los estudiantes mediante firmas o marcas de "revisado", "entregado" o "cumplido".

En la revisión de literatura se identificaron algunas características que promueven una retroalimentación efectiva: correspondencia con los objetivos de aprendizaje y los criterios de éxito de la consigna; contraste entre el desempeño actual de los estudiantes y el logro de aprendizaje deseable (Brookhart, 2017; Brooks et al., 2019; Bruno, Santos, 2010; Chappuis et al., 2014; Hattie, Timperley, 2007; Hounsell et al., 2008; Parr, Timperley, 2010); descriptiva, brindando información detallada de las fortalezas y debilidades del trabajo de los alumnos en lugar de únicamente emitir juicios, asignar calificaciones o enfatizar lo que no hicieron los estudiantes en la elaboración de la consigna (Chappuis et al., 2014; García et al., 2011; Lipnevich, Smith, 2009; Timperley, 2013); promoción de corrección de errores y búsqueda de soluciones, sugiriendo únicamente lo necesario para que los alumnos realicen dicha búsqueda por sí mismos (Black, Wiliam, 1998; Parr, Timperley, 2010; Chappuis et al., 2014; Bruno, Santos, 2010; García et al., 2011); específica y precisa, focalizada en aspectos concretos de la consigna, con un grado intermedio de generalización, evitando elogios y demasiados comentarios (Wiggins, 1998; Black, Wiliam, 1998; Chappuis et al., 2014; Bruno, Santos, 2010; Brookhart, 2017); oportuna, brindándose en el momento que permita la mejora de los aprendizajes de los estudiantes y adaptada a la audiencia a la que se dirige (Chappuis et al., 2014; Bruno, Santos, 2010; Brookhart, 2017; García et al., 2011; Shute, 2008).

También se ha precisado que la retroalimentación puede estar centrada en el proceso (Black, Wiliam, 1998) o en el producto (Hattie, Timperley, 2007); la retroalimentación del proceso favorece la autorregulación del aprendizaje, aunque la retroalimentación orientada al resultado final también es útil, ya que sirve para construir adecuadamente el proceso de autorregulación y tiene mayor potencial si se combina con la retroalimentación al proceso. 


\section{La retroalimentación de la escritura}

En la producción de textos escritos, la retroalimentación permite al escritor saber si ha comunicado lo que buscaba expresar y, de no ser así, qué discrepancias observa el lector en el texto (Sommers, 1982). La retroalimentación en esta área del conocimiento representa la visión del lector, cuyas preguntas y comentarios ayudan al alumno a mejorar su texto, su proceso de escritura y, al mismo tiempo, le permiten consolidar un control sobre su proceso de aprendizaje y de escritura (Sommers, 1982).

Parr y Timperley (2010) indican que uno de los medios privilegiados para retroalimentar la escritura de los estudiantes son los comentarios escritos, sin embargo, estos también pueden representar una práctica problemática. De acuerdo con estudios citados por estas investigadoras (Hyland, 2000; Municie, 2000; Kluger, DeNisi, 1998), la efectividad de los comentarios escritos es baja, debido a que los profesores tienden a carecer de conocimientos acerca del funcionamiento de la escritura (Moats, 2000; Moats, Lyon, 1996; Wong-Fillimore, Snow, 2002, en Parr, Timplerley, 2010), además de enfrentar dificultades para especificar lo que implica un desempeño esperado en esta área del conocimiento. Por ejemplo: establecer criterios de éxito para valorar la construcción de argumentos en un texto informativo, i.e. claridad del argumento y uso de evidencias para sustentarlo.

La falta de efectividad de los comentarios escritos, sostienen Parr y Timperley (2010), también se atribuye a que los docentes se centran en cualidades personales de los estudiantes o no les dan suficiente información para mejorar. Por ejemplo, un comentario como "tienes mucha creatividad para redactar", puede aludir a una característica personal, pero no al producto elaborado; o, al anotar "necesitas trabajar en la coherencia de tu texto", no se brinda información acerca de qué aspectos específicos de la coherencia (estructura del texto o los párrafos, selección y progresión de ideas, entre otros) forman parte un desempeño óptimo en la construcción de un texto, y que son, en última instancia, lo que un estudiante podría usar para realizar modificaciones o como insumo en trabajos futuros.

Algunos investigadores también señalan que los docentes tienden a focalizar sus comentarios en cuestiones técnicas o superficiales, en detrimento de las cuestiones más profundas como la construcción de significados que hacen los alumnos (Connors, Lunsford, 1993; Sommers, 1982; Hargreaves, McCallum, 1998, en Parr, Timperley, 2010). Por ejemplo: un docente solicita al alumno elaborar una estructura para un texto narrativo, y los comentarios que registra se centran en los errores ortográficos y no en la secuencia y articulación de ideas.

De acuerdo con Parr y Timperley (2010), una de las características que deben tener los comentarios escritos para contribuir de manera efectiva al desarrollo de las habilidades de escritura de los alumnos, es que les indiquen de manera específica cuáles son los criterios de éxito o las características de un trabajo de calidad. También es necesario que estos les ayuden a ver

Diálopos sobre Educación año 12 | número 23 | julio-diciembre 2021 | ISSN 2007-2171 
dónde están con respecto a lo que tienen que lograr y les señalen qué hacer para poder cerrar la brecha entre su desempeño actual y el deseable.

La revisión de trabajos escritos ocupa un lugar importante en el trabajo cotidiano de los docentes (Elliot et al., 2016). En la literatura anglosajona se utiliza el término "marking" o "grading" para denominar la "actividad de revisar y corregir el trabajo escrito de los alumnos" (Oxford University Press, 2020). En este artículo se usará el término revisión de trabajos escritos, entendiendo que puede comprender el registro de comentarios, la corrección de equivocaciones de los alumnos y la asignación de calificaciones.

La revisión de trabajos escritos puede brindar beneficios a los docentes y a los alumnos; a los docentes les permite valorar el entendimiento logrado por los alumnos y realizar ajustes en sus prácticas para promover su mejora; a los estudiantes les da información sobre su desempeño y, si esta información es clara, puede llevarlos a implementar acciones para su mejora (Goh, 2019). A pesar de estos beneficios, la revisión de textos escritos puede convertirse en una carga de trabajo inmanejable, dependiendo del enfoque que adopten los docentes, por ejemplo, con respecto a la frecuencia y tipo de retroalimentación que se brinda.

El estudio de Elliot et al. (2016) acerca de la evidencia de investigación sobre la revisión de trabajos escritos, distingue la retroalimentación que puede brindarse a los alumnos de acuerdo con su especificidad y precisión. En un extremo se encuentra la retroalimentación genérica o imprecisa, como: marcar como entregado un trabajo (i.e. "entregado", "revisado"); registrar elogios comunes (i.e. "bien hecho", "buen esfuerzo"); o la asignación de una calificación numérica. Este tipo de retroalimentación se ha encontrado que no es efectiva para la mejora del desempeño de los alumnos, pues no les permite saber qué tienen que mejorar.

En el otro extremo está la retroalimentación específica, que incluye la identificación de los referentes para la evaluación y la forma de hacer las anotaciones. En la literatura se ha encontrado que la definición de objetivos de desempeño específicos y de criterios de éxito en la realización de los trabajos escritos puede ser efectiva en la mejora de los aprendizajes de los alumnos, orientándolos en el desarrollo de las tareas y también en su corrección (Elliot et al., 2016). Para esto, se sugiere que los docentes distingan en los trabajos de los alumnos aquellos errores esporádicos que pudieron deberse a un descuido, de aquellos que revelan un patrón sistemático y que podrían estar vinculados a un entendimiento equivocado; ante los primeros, se recomienda que los docentes marquen el error pero sin corregir, para que los alumnos realicen esta tarea; en el error del segundo tipo, es deseable que los docentes den pistas para que los alumnos lo identifiquen por sí mismos y realicen las modificaciones pertinentes; estas pistas pueden ser preguntas, así como principios o reglas tratados en clase. Además, los docentes deben elegir si hacer una corrección minuciosa o focalizada; por ejemplo, pueden priorizar la revisión de la manera en que los alumnos construyen los argumentos, en vez de enfocarse en múltiples elementos del texto (v.gr. ortografía, uso de vocabulario, contenido, organización del 
texto, etc.); también podrían elegir retroalimentar la entrega parcial de un trabajo extenso de manera minuciosa, para que los alumnos tengan suficientes elementos para corregirla y entregar la versión definitiva; o focalizarse en criterios de desempeño específicos.

El reporte de Elliot et al. (2016) muestra que la retroalimentación de trabajos escritos va más allá del registro de comentarios o marcas, pues para promover un cambio en los aprendizajes es necesario que: se dé tiempo a los alumnos para entender y responder a las observaciones de los docentes; se construyan oportunidades de conversación entre docentes y alumnos en relación con las observaciones; y se promueva la modificación de los trabajos en función de la retroalimentación. También hay evidencia de que las prácticas de revisión de trabajos escritos están vinculadas a decisiones escolares (v.gr. la frecuencia con la que se solicita que los docentes revisen los trabajos de los alumnos, y el tipo de retroalimentación que se pide que den en cada escuela) y la capacitación que tengan para hacer este tipo de revisiones.

\section{Metodología y desarrollo}

Diseño y técnicas de obtención de información

Esta investigación se diseñó como un estudio de caso. Se optó por este diseño metodológico, dado que permite "[...] la comprensión en profundidad de un objeto, hecho, proceso o acontecimiento en su contexto natural" (Rovira, 2004: 11). Se adoptó un enfoque cualitativo, ya que brinda la oportunidad de construir una descripción rica en detalles de un objeto de estudio, a través de las prácticas, conocimientos y significados subjetivos que los individuos dan a ese objeto en un contexto específico (Flick, 2004). Para este trabajo se emplearon dos técnicas de obtención de información: 1) análisis de los trabajos producidos por los estudiantes y evaluados por la docente; y 2) entrevistas semiestructuradas con la profesora y sus alumnos. ${ }^{1}$

Los trabajos de los estudiantes corresponden a los productos finales del segundo proyecto didáctico del bloque 2 de los Programas de Estudio 2011. Guía para el maestro. Educación Básica. Secundaria. Español (SEP, 2011). El proyecto didáctico fue seleccionado en función de su focalización en la producción de textos escritos. Cabe mencionar que, aunque en el programa de la asignatura se incluían varios proyectos cuyo producto final era un texto, no todos se concentraban en el proceso de producción de textos escritos; en algunos casos, el texto era una forma de reportar otras actividades o procesos, por ejemplo: el objetivo del tercer proyecto del bloque 1 de tercer grado de secundaria radicaba en que los estudiantes analizaran el efecto de los mensajes publicitarios por medio de encuestas, lo que se comunica a través de un texto escrito, aunque la finalidad del proyecto no es el proceso de escritura sino el análisis de un tipo de texto específico. Se recolectaron 32 textos escritos elaborados por los estudiantes, una vez que fueron evaluados por su profesora.

1 Este trabajo deriva de una investigación mayor, en la que se utilizaron otras técnicas de obtención de información como la observación en el aula.

Diólogos sobre Educación 
Las entrevistas semiestructuradas tuvieron como propósito conocer las interpretaciones de los estudiantes acerca de la retroalimentación que recibieron en sus producciones y las percepciones de la docente sobre sus propias prácticas de retroalimentación. Las entrevistas se condujeron después del análisis de las producciones escritas; en las entrevistas se retomaron muestras de diferentes recursos empleados en la retroalimentación como un insumo para plantear las preguntas.

\section{Participantes}

La investigación se desarrolló en una escuela secundaria general de la ciudad de Aguascalientes, durante el segundo bimestre del ciclo escolar 2014-2015 y participó una profesora que al momento de la recolección de datos impartía la asignatura de Español en segundo grado, bajo los Programas de Estudio 2011. Guía para el maestro. Educación Básica. Secundaria. Español (SEP, 2011).

Los criterios para seleccionar a la docente fueron: que el grupo estuviera por desarrollar un proyecto didáctico focalizado en la producción de textos escritos, así como la disposición de la profesora para participar en la investigación. En la última etapa del estudio se realizaron entrevistas con tres estudiantes, a fin de conocer los significados que atribuían a las prácticas de retroalimentación que se llevaron a cabo durante el proyecto didáctico. La selección de los estudiantes, para quienes se utilizarán los seudónimos de Sofía, Emiliano y Catalina por cuestiones de anonimato y confidencialidad, se llevó a cabo tomando en cuenta los siguientes criterios: 1) las calificaciones asignadas a los textos de los alumnos, se eligió uno de los trabajos con las calificaciones más altas y uno con la nota numérica más baja; y 2) los comentarios escritos de la docente, se consideró necesario indagar en las interpretaciones de los estudiantes acerca de los comentarios escritos que la profesora hizo a sus trabajos, sobre todo, cuando estos parecían ser imprecisos, poco específicos o poco descriptivos.

\section{Análisis}

Se realizó un análisis por categorización, con categorías establecidas a priori construidas a partir de la revisión de la literatura científica. Dichas categorías, listadas a continuación, representan rasgos de una retroalimentación efectiva y permitieron valorar las prácticas de la docente en función de su potencial para promover el aprendizaje de los estudiantes:

1. Correspondencia con los objetivos de aprendizaje y los criterios de éxito de la consigna.

2. Contraste que ofrece entre el desempeño actual de los estudiantes y el logro de aprendizaje deseable, y debe brindar estrategias para cerrar la brecha entre ambos.

3. Naturaleza descriptiva, proporcionando información detallada de las fortalezas y debilidades del trabajo de los alumnos, en lugar de únicamente emitir juicios, asignar calificaciones o enfatizar lo que no hicieron los estudiantes. 
4. Promoción de corrección de errores y búsqueda de soluciones, sugiriendo únicamente lo necesario para que los alumnos realicen dicha búsqueda por sí mismos.

5. Precisión y especificidad, focalizando en aspectos concretos de la consigna, tiene un grado intermedio de generalización, evitando elogios y demasiados comentarios.

6. Enfoque en el proceso o en el producto.

\section{Cuidados de la calidad de la información}

Con la finalidad de garantizar la calidad de los hallazgos presentados en este trabajo, se utilizaron tres de las estrategias de validación de la información recomendadas por Creswell y Poth (2018). La primera fue la corroboración de las evidencias a través de la triangulación de múltiples fuentes de información. Para ello, se emplearon los datos obtenidos de las entrevistas con la profesora y los estudiantes, lo que ayudó a validar las interpretaciones derivadas del análisis de los textos evaluados por la docente. La segunda estrategia consistió en la revisión por pares, la cual se llevó a cabo en sesiones de trabajo documentadas, en las que la segunda autora de este artículo fungió como revisora del análisis realizado por la primer. La tercera estrategia consistió en validar la información por medio de la retroalimentación de los participantes. Se proporcionó a la profesora un reporte de los resultados preliminares de la investigación, con el fin de conocer sus opiniones y observaciones acerca de la precisión y credibilidad de las interpretaciones y hallazgos plasmados en el estudio. Después de una semana, lapso que se dio a la docente para revisar el reporte, se tuvo una reunión con ella para comentar sus observaciones al documento, mismas que fueron grabadas en audio con autorización de la profesora y, posteriormente, integradas a la investigación.

\section{Resultados}

La práctica social del lenguaje ${ }^{2}$ del proyecto didáctico elegido señala que el alumno debe escribir variantes de un mismo cuento, a través de los siguientes aprendizajes esperados: "1) modifica las características de los diferentes aspectos en función de la historia que presenta un cuento original; 2) modifica la estructura del cuento e identifica sus implicaciones en el efecto que causa; 3) emplea recursos lingüísticos para describir personajes, escenarios y situaciones" (SEP, 2011: 66).

Los Programas de Estudio 2011. Guía para el maestro. Educación Básica. Secundaria. Español (SEP, 2011) proponen varias actividades para el desarrollo de cada uno de los proyectos didácticos. En este caso, los alumnos debían realizar una serie de consignas antes de redactar los textos en su versión final: 1) lectura de cuentos, 2) selección de cuentos, 3) cuadro descriptivo de mo-

2 De acuerdo con la Secretaría de Educación Pública (2011: 47), las prácticas sociales del lenguaje son “[...] pautas o modos de interacción; de producción e interpretación de prácticas orales y escritas; de comprender diferentes modos de leer, interpretar, estudiar y compartir textos; de aproximarse a su escritura, y de participar en intercambios orales".

Diálopos sobre Educación 
dificaciones a los cuentos, 4) la planificación de los cuentos a escribir, y 5) los borradores de los cuentos. En el caso estudiado se realizaron todas estas actividades, a excepción de la planificación de los cuentos.

Para fines de este artículo, se optó por analizar únicamente las versiones finales de los textos, dado algunas de las consignas del proyecto, como que la lectura y selección de cuentos no fueron objeto de evaluación y retroalimentación por la docente. En cuanto a los cuadros descriptivos de modificaciones de los cuentos, producto de la tercera actividad, se identificó que no todos fueron evaluados por la docente, y en aquellos que recibieron algún tipo de valoración solo se encontró una firma o un comentario, lo que no aportaba información suficiente para analizar las prácticas de retroalimentación. Con respecto a los borradores de los cuentos, se observó que el avance de los alumnos fue diferenciado, por lo que no todos concluyeron la consigna y se contaba con pocas evidencias derivadas de esta.

Dado que este trabajo se enfoca en el análisis de la retroalimentación que la profesora proporcionó a las versiones finales del trabajo de los alumnos, se reconocen las limitaciones de esta investigación pues no permite dar cuenta de la manera en que los estudiantes pudieron haber usado la información recibida, incorporando correcciones y mejoras a los textos que elaboraron en el marco de esta consigna, así como en tareas de escritura posteriores. Sin embargo, después del proyecto didáctico en que se circunscribe este estudio, se desarrollarían otros en los tres bloques curriculares restantes, por lo que no se descarta que la profesora y los alumnos pudieron haber tomado decisiones orientadas a la mejora a partir de la retroalimentación.

\section{¿Qué recursos se utilizaron para dar retroalimentación a los alumnos \\ en sus trabajos escritos?}

Se identificaron tres recursos, a través de los cuales se realizó la retroalimentación: 1) comentarios escritos; 2) marcas gráficas (palabras subrayadas, encerradas en círculos, barras oblicuas y correcciones ortográficas, específicamente, de acentuación y uso de grafías); y 3) calificaciones. El uso de estos tres recursos es consistente en gran parte de las evidencias recopiladas, dado que 31 textos presentan una calificación numérica, 27 tienen una o varias notas escritas y 26 cuentan con señalamientos gráficos. En 22 de los textos se utilizaron tres recursos de retroalimentación; en 8 se identificaron dos elementos (todos con una nota numérica, 5 tienen una o varias notas escritas y en 3 se observan marcas gráficas); y 2 de los trabajos cuentan con un recurso (uno tiene calificación y otro con marcas gráficas).

Cabe señalar que se incluyen las calificaciones como un recurso para brindar retroalimentación a los alumnos, debido a que en la literatura se ha encontrado que es "el tipo de retroalimentación que más reciben los estudiantes, frecuentemente con pocos comentarios o sin comentarios adicionales" (Lipnevich y Smith, 2009: 320). Esto ha hecho que algunos autores apunten a que la retroalimentación se enmarca dentro de la asignación de calificaciones (Broo- 
khart, 2017), en la que una nota, alfabética o numérica, resume el desempeño de los alumnos, y se añaden comentarios descriptivos, evaluativos o afectivos sobre lo que se revisa.

La función formativa de las calificaciones ha sido cuestionada ampliamente en la literatura. Estudios realizados desde la década de los años ochenta mostraron que las calificaciones podrían afectar negativamente el desempeño de los estudiantes, por ejemplo, reduciendo su interés sobre las tareas a desarrollar, fomentando ansiedad o limitando su creatividad (Butler, Nisan, 1986). En metanálisis recientes se han encontrado efectos variados al contrastar alumnos que no reciben retroalimentación alguna, quienes reciben solo calificaciones y quienes reciben comentarios descriptivos; se ha identificado que las calificaciones conllevan un mejor desempeño que la ausencia de retroalimentación, pero quienes solo reciben calificaciones pueden experimentar una menor motivación intrínseca para realizar las tareas y una mayor motivación extrínseca cuyo efecto no perdura; los estudiantes que reciben comentarios, en cambio, experimentan una mayor motivación intrínseca y menor motivación extrínseca, y muestran un mejor desempeño (Koenka et al., 2019).

\section{Los comentarios escritos para retroalimentar la escritura}

Se identificó un total de 44 notas escritas distribuidas en 27 de los textos de los alumnos; cada trabajo presenta entre uno y cuatro comentarios escritos: cinco textos no tienen ninguna nota; en 16 se observó solo un comentario; siete cuentan con dos notas de este tipo; en dos se encontraron tres de estas y otros dos trabajos tienen cuatro.

Se observó que 31 de los comentarios escritos enfatizan aquello que los estudiantes no lograron en el desarrollo de la consigna; estas notas escritas no brindan información a los alumnos sobre lo que lograron con respecto a lo que se esperaba u orientaciones para avanzar en su aprendizaje, por lo tanto, se considera que no son descriptivas. En la siguiente imagen se muestra un ejemplo de este tipo de comentarios; en ella se puede observar que la docente registró limitaciones del trabajo ("faltó desarrollo","no hubo clímax", "no entrelazas acciones"), sin elaborar sobre lo que logró hacer y su relación con los aprendizajes esperados. 
Imagen 1. Ejemplo de comentario escrito focalizado en carencias del texto

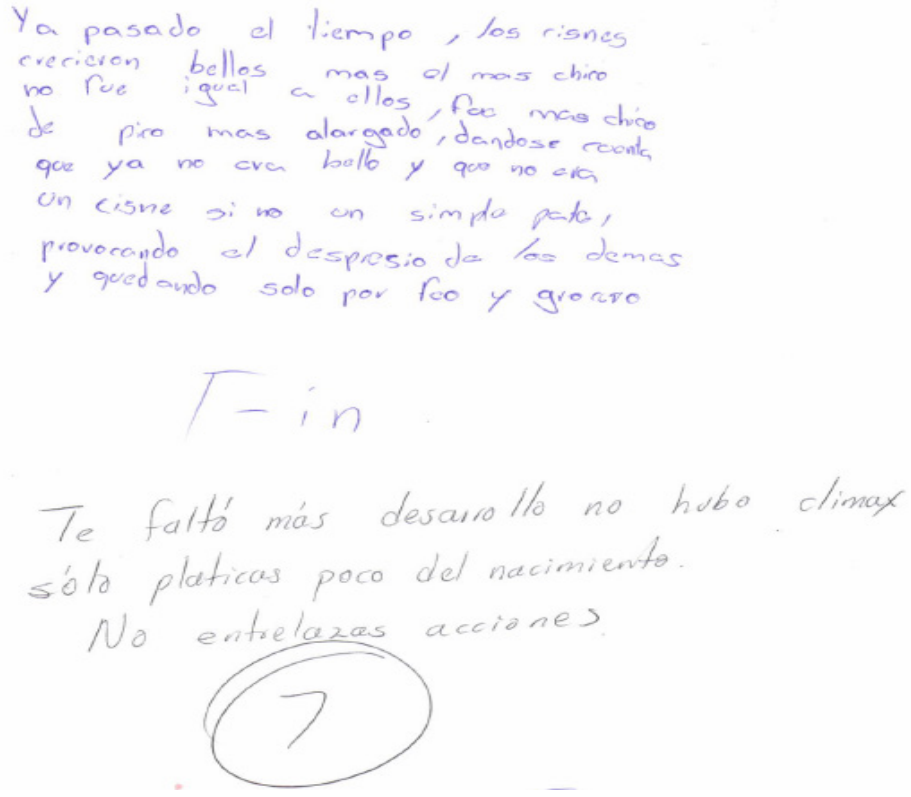

21 de estas 31 notas también son imprecisas o poco específicas, ya que no permiten a los alumnos identificar en qué parte del texto se encuentra el error. Otros comentarios podrían ser vagos para los alumnos. En dos notas la docente indicó: "Un clímax emocionante?"; en estos casos, no es claro lo que se buscaba comunicar. En otro comentario solo se registró "título", lo que podría señalar que en el texto falta este elemento, pero no se puede asegurar que fuera lo que la profesora pretendía que comprendiera el alumno. Los comentarios poco precisos pueden ser ambiguos para los alumnos, obstaculizando su comprensión de la retroalimentación y reduciendo sus oportunidades para mejorar su desempeño.

Otros comentarios que comunican información imprecisa son los elogios, encontrados en siete de los textos. Los elogios, si bien buscan alabar cualidades o méritos del producto escrito o del alumno, tienden a ser generales y, por tanto, imprecisos, ya que no permiten a los alumnos identificar sus logros, sus áreas de oportunidad y las estrategias de mejora que pueden utilizar. Por ejemplo, el comentario "Buena transformación de la historia real" no permite saber qué hizo el estudiante para lograr que la transformación sea valorada de esa manera, y esto limita las oportunidades de que en un escrito futuro se empleen estrategias similares.

También se advirtió que algunas notas escritas se referían a conceptos amplios, como la coherencia ( 11 comentarios) ${ }^{3}$ o los elementos estructurales de los cuentos ( 10 comentarios). ${ }^{4}$ Estos conceptos, sin criterios que hayan sido comunicados a los alumnos previamente, no facili-

3 Cuatro de estos comentarios se refieren directamente a la carencia de coherencia, 6 aluden a la falta de claridad en algunas partes del texto y uno a la presencia de ideas inconclusas. Hay dos comentarios que señalan, al mismo tiempo, la falta de claridad y de coherencia. 4 Estas notas aluden a cuestiones como la falta de trama, de conflictos, de clímax y algunas limitaciones para entrelazar acciones. 
tan su comprensión, los estudiantes podrían no entender a qué se alude con este tipo de términos y qué aspectos específicos comprendió su evaluación. En la siguiente imagen se muestra un comentario que incluye los conceptos señalados: "coherencia" y "trama"; no se brinda información adicional al estudiante para entender qué hizo que la docente los valorara de esa manera o cómo puede mejorar su desempeño en textos posteriores.

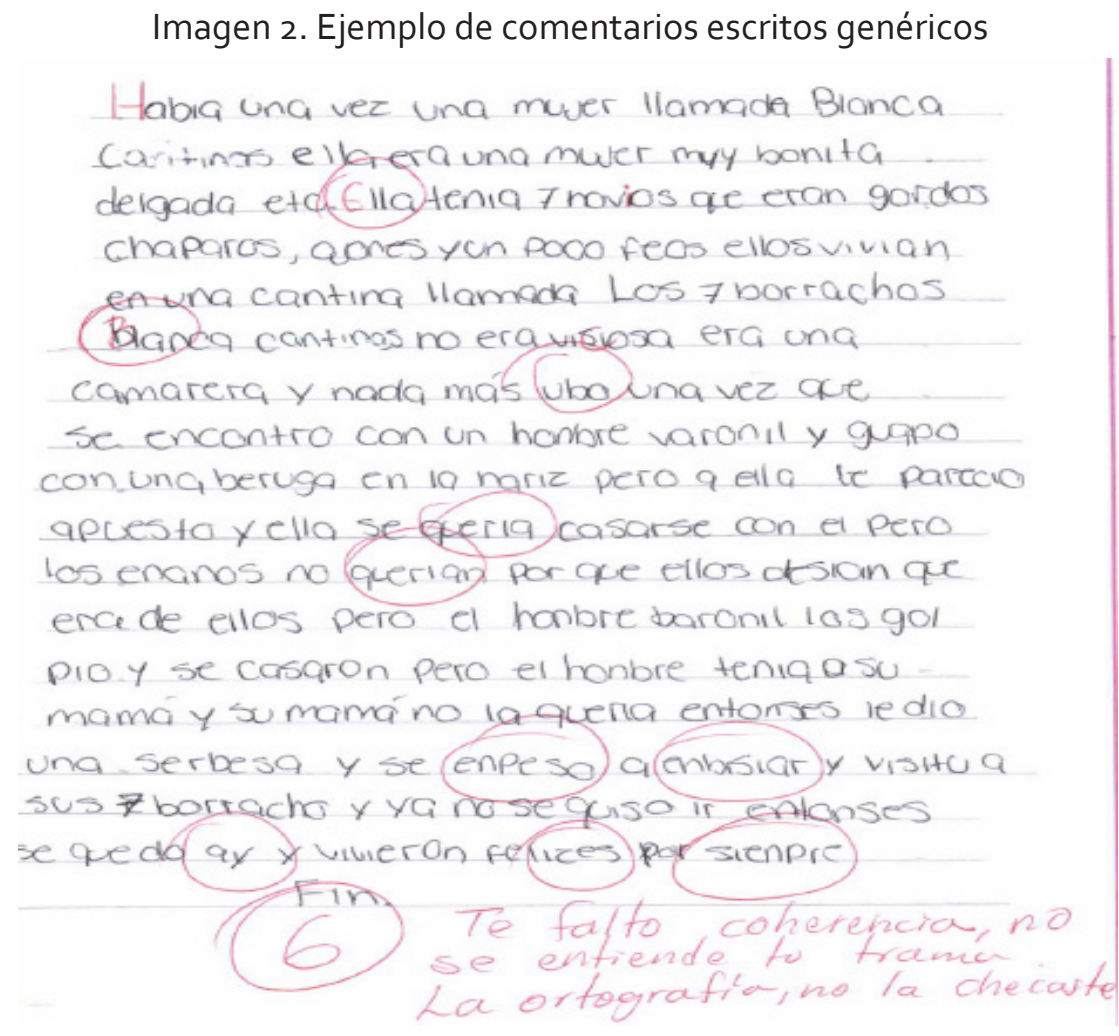

Durante el desarrollo del proyecto didáctico, la docente señaló a los estudiantes que en sus textos escritos deberían cuidar la coherencia, la ortografía, la estructura y las descripciones. En la entrevista, la profesora volvió a señalar algunos de estos aspectos como parte importante de la evaluación al trabajo de sus alumnos: "por ejemplo del cuento, les valoro que cuente con las partes que vimos: inicio, desarrollo, clímax. Yo les valoro todo eso, les valoro ortografía... [...] les valoro coherencia, les valoro su presentación [...]". Aunque se puede decir que los estudiantes conocían algunos de los elementos que se priorizaron en la evaluación y retroalimentación de sus textos, no se encontraron evidencias sobre criterios de éxito u objetivos de aprendizaje de cada uno de estos aspectos en el marco de la consigna.

A propósito de la correspondencia entre los objetivos de aprendizaje, los criterios de éxito y la retroalimentación, cabe señalar que la docente compartió con los alumnos los tres aprendizajes esperados del proyecto didáctico, sin embargo, no se encontraron comentarios rela-

Diálopos sobre Educación 
cionados con ellos. Si bien se observó que varias de las notas escritas giran en torno a los elementos estructurales de los cuentos (10 comentarios), por ejemplo: "Te faltaron entrelazar más acciones, problemas, etc.", "Te faltó más trama", estas no se vinculan con las modificaciones a las características o estructura del cuento, ni se refieren al efecto que estas transformaciones causan en el lector. También se detectaron comentarios relacionados con el uso de descripciones (4 notas), como: "Te faltó describir a tus personajes", "No describes”, pero ninguno menciona los recursos lingüísticos para realizar dichas descripciones (uso de adjetivos, uso de sinónimos y el empleo de voces narrativas). ${ }^{5}$

Por otra parte, se identificaron ocho comentarios que aluden a objetos de evaluación ajenos a la consigna, es decir, no tienen correspondencia con los aprendizajes esperados del proyecto didáctico y tampoco con lo que estableció la docente en el aula, por lo que posiblemente no brindaron información útil y precisa a los estudiantes para mejorar su desempeño académico. Estas notas se refieren a rasgos personales de los alumnos, como su creatividad e imaginación, o su capacidad para hacer una historia interesante o emocionante, por ejemplo: "Te faltó darle más interés a tu historia", "Te faltó más creatividad al escribir tu cuento”.

Imagen 3. Ejemplo de comentarios que aluden a rasgos distintos a los objetos de evaluación

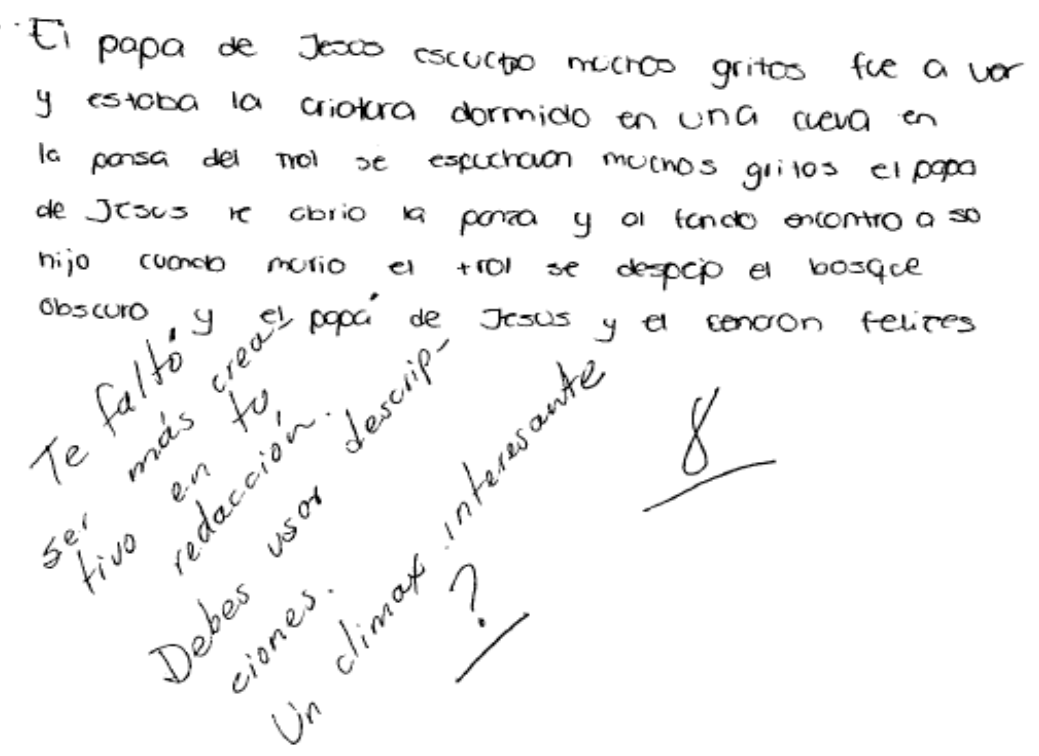

Es importante señalar que no se encontraron comentarios que ofrecieran a los estudiantes un contraste entre su desempeño actual y los objetivos de aprendizaje de la consigna, ni es-

5 Existe variación en la manera de abordar los contenidos en cada uno de los libros de texto que se utilizan en secundaria. En el caso estudiado, el grupo empleó el libro Español 2. Comunico lo que pienso (Lodoño, 2013), en el que se hace referencia a estos recursos lingüísticos, mismos que pueden variar en otras obras. 
trategias para cerrar la brecha entre ambos, sin embargo, se detectaron dos notas que brindan algunas orientaciones al trabajo de los estudiantes. Por ejemplo: "Repites las mismas palabras, busca sinónimos", "Debes usar sinónimos y así no repites la palabra”. En los textos en los que se encontraron estos comentarios, también se identificaron marcas gráficas que indican algunas de las palabras que fueron repetidas, lo que podría brindar información útil a los alumnos para identificar en qué parte de su trabajo necesitan hacer estas modificaciones.

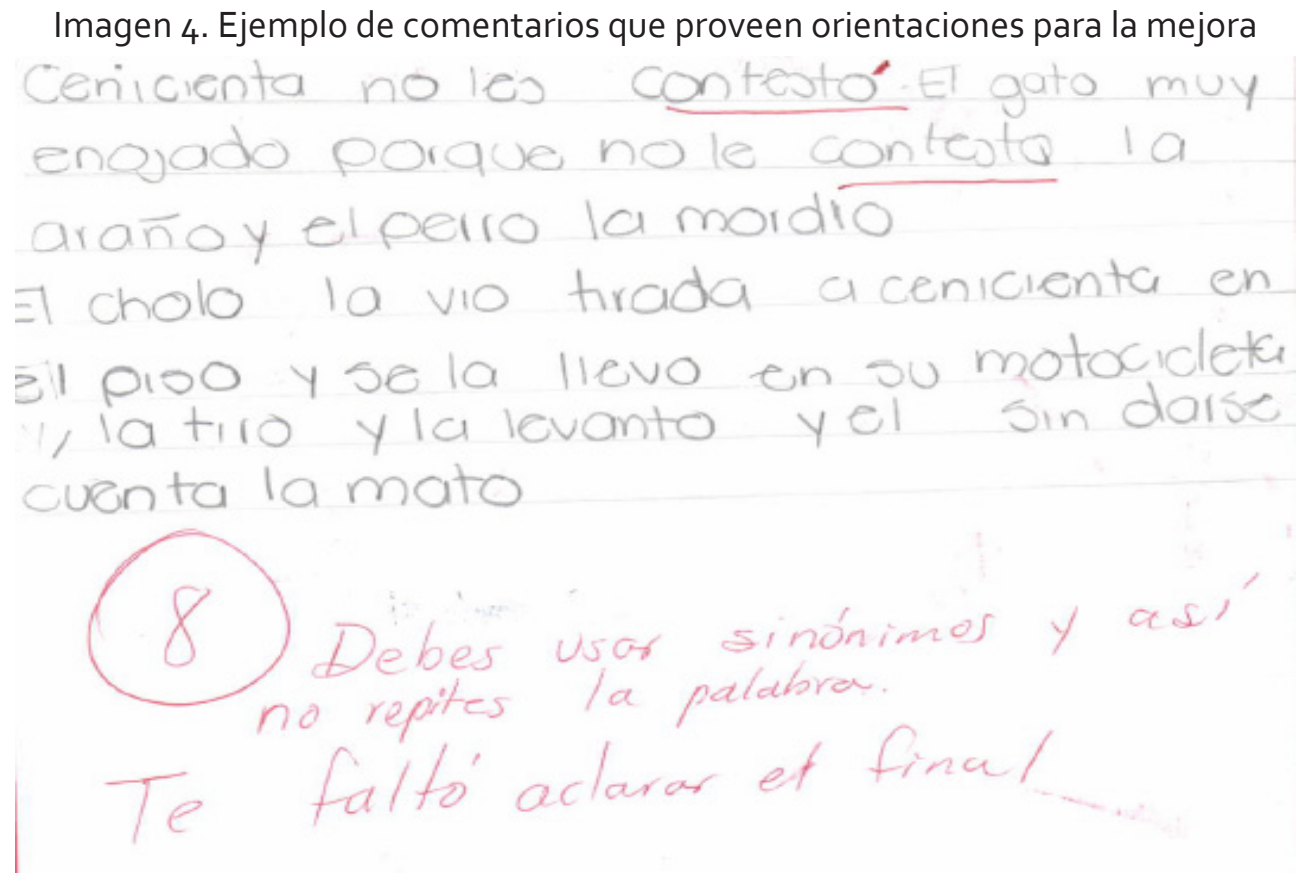

\section{Marcas gráficas como medio de retroalimentación}

En los trabajos escritos de los estudiantes se encontraron diferentes marcas gráficas colocadas por la docente: a) palabras encerradas en círculos; b) palabras subrayadas; c) correcciones a diferentes palabras (acentuación y uso de grafías); y d) barras oblicuas. A excepción de seis de los textos analizados, el resto cuenta, al menos, con uno de estos señalamientos.

Las palabras encerradas en círculos parecen indicar algún error ortográfico. En algunos casos la profesora circuló la parte del vocablo en la que se encontraba el error, lo que podría brindar pistas a los alumnos para detectar sus áreas de oportunidad y hacer las modificaciones pertinentes, aunque la práctica que prevaleció fue que la docente corrigió las palabras colocando los acentos faltantes o la grafía correspondiente; esto se observó en 22 de los textos. La corrección de los errores por los docentes puede limitar el potencial de la retroalimentación para promover la búsqueda de soluciones por parte de los alumnos, pues en la literatura científica se ha encontrado que proveer una respuesta correcta evita que los estudiantes reflexionen sobre sus equivocaciones y no reduce la probabilidad de que los errores se repitan en el futuro (Elliot et al., 2016).

Diálo pos 
Imagen 5. Ejemplo de correcciones señaladas con marcas gráficas en las producciones escritas

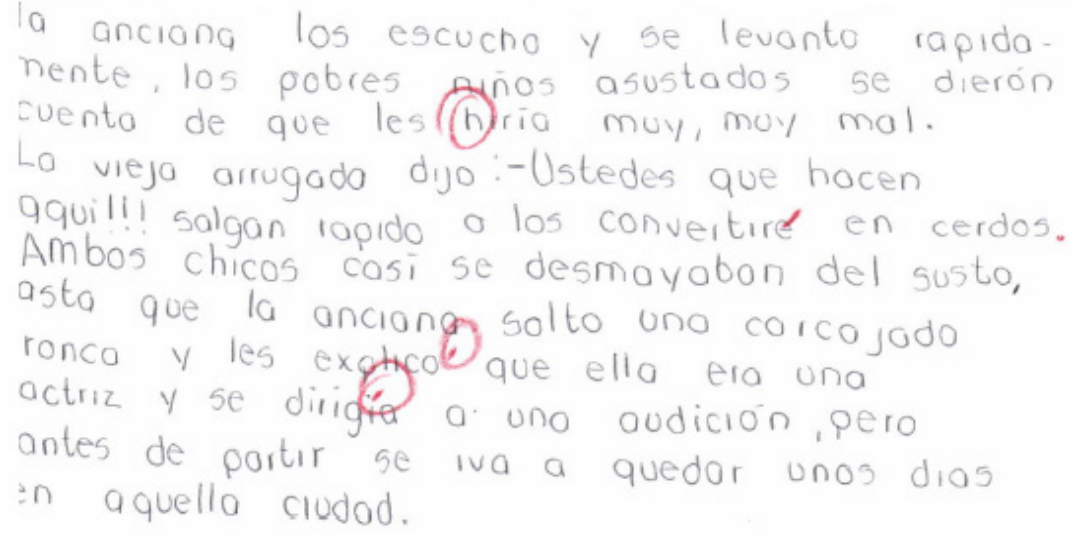

El subrayado parece haber sido usado por la profesora para señalar la repetición de algunas palabras. En el siguiente ejemplo se muestra una palabra subrayada en dos oraciones consecutivas; esta marca gráfica, por sí misma, podría no haber sido entendida por los alumnos, solo en dos textos se complementó con un comentario escrito que alude a la búsqueda de sinónimos para evitar la repetición de palabras.

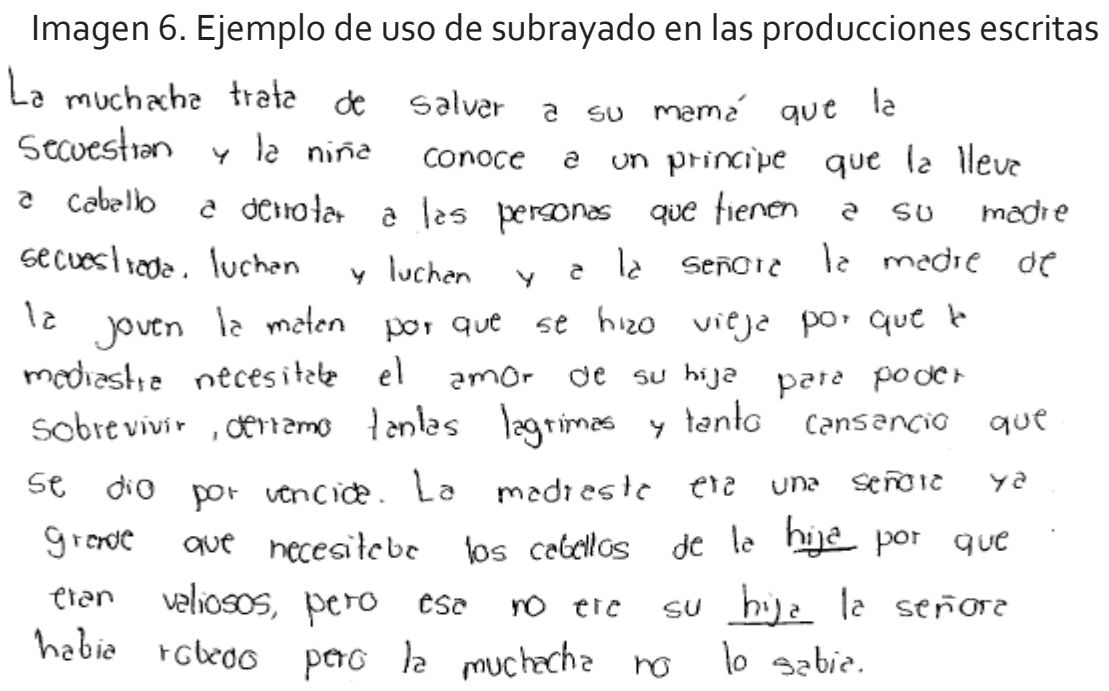

En la revisión de los productos escritos se advirtió un uso inconsistente de las marcas gráficas para retroalimentar el trabajo de los alumnos, ya que en ocasiones la docente circuló algunas palabras para indicar su repetición o subrayó otras para señalar errores ortográficos, lo que podría haber comunicado información confusa a los estudiantes.

En suma, las correcciones que realizó la profesora a los textos de los alumnos a través de marcas gráficas se enfocaron en la acentuación y el uso de grafías, sin embargo, no se pro- 
porcionaron pistas que les dieran la posibilidad de detectar el error por sí mismos y corregirlo posteriormente. Asimismo, parece haber una falta de sistematicidad para llevar a cabo tanto el señalamiento de faltas ortográficas como su corrección, dado que no se distingue entre errores esporádicos, posiblemente atribuidos a algún descuido, y aquellos que podrían obedecer a algún patrón. También se encontró que en ninguno de los trabajos analizados la revisión de la docente fue exhaustiva, es decir, por lo general, los textos presentan un mayor número de errores ortográficos de los que la profesora señaló y corrigió, lo que podría derivar en que los estudiantes no cuenten con información suficiente para mejorar sus habilidades de escritura. Si bien es cierto que llevar a cabo la revisión de una gran cantidad de textos considerando todos los aspectos ortográficos, además de las otras propiedades textuales de estos, puede ser una empresa imposible, como señalan Elliot et al. (2016); la profesora pudo haber optado por una revisión focalizada de los textos, centrándose solo en algunas de sus propiedades. La ventaja de la focalización en la revisión de los textos escritos (por ejemplo, marcar solo los errores en acentuación de verbos conjugados en pasado simple), comunicada previamente a los alumnos, constituye una pista en sí misma, que los puede ayudar a comprender una regla, corregir sus textos y emplearla en productos futuros.

En menor medida se identificaron barras oblicuas, las cuales fueron utilizadas para indicar a los alumnos la necesidad de separar o unir algunas palabras (véase la imagen 7).

Imagen 7. Ejemplo de uso de barras oblicuas en la revisión de producciones escritas

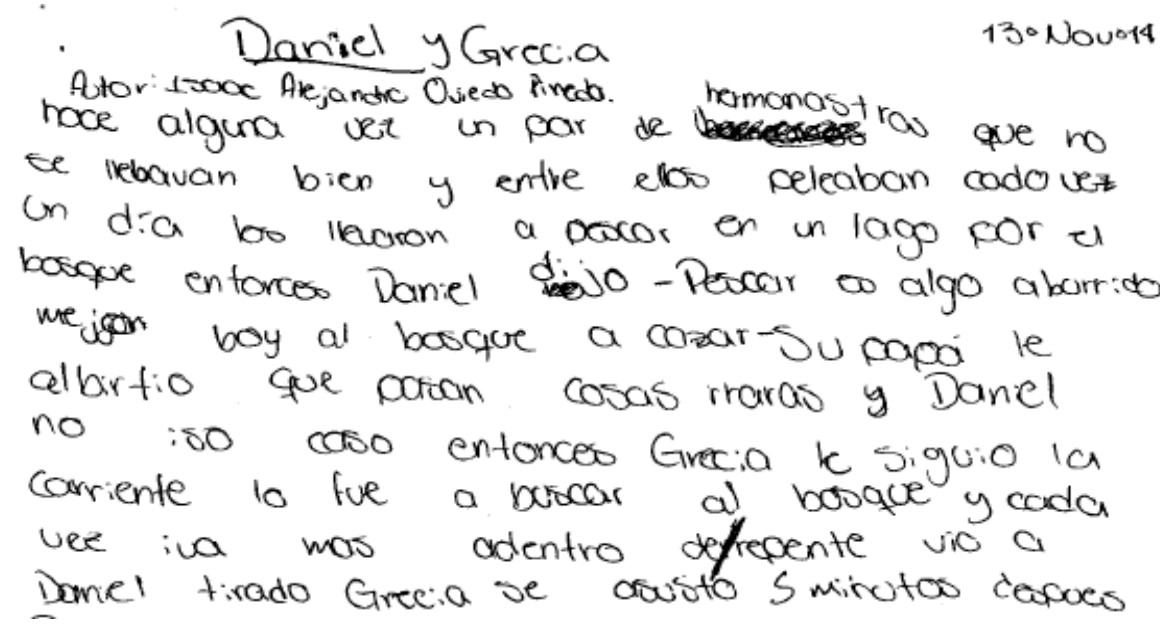

Cabe señalar que se observó que en los trabajos con las calificaciones más altas (9 y 10), la docente colocó un menor número de marcas gráficas (máximo 8) en comparación con los textos a los que calificó con 6,7 u 8, mismos que tienen una mayor cantidad de este tipo de señalamientos (hasta 27 en un solo texto). Al analizar los trabajos de los estudiantes, se encontró que 
aquellos con las notas numéricas más altas no necesariamente presentan menos errores que el resto, lo que parece indicar que la docente posiblemente consideró otros criterios para realizar la retroalimentación; esto podría ser objeto de futuras indagaciones.

\section{Las calificaciones asignadas al trabajo de los estudiantes y su articulación con los otros recursos para brindar retroalimentación}

Las calificaciones fueron el recurso más utilizado para brindar retroalimentación; 31 de los 32 textos analizados tienen una nota numérica. El único trabajo que no fue calificado, tampoco recibió comentarios escritos pero tiene marcas gráficas: una palabra circulada, lo que indica un error ortográfico corregido por la profesora.

Las calificaciones asignadas oscilaron entre el 6 y el 10, distribuidas de la siguiente manera: uno de los trabajos obtuvo un 6; a 10 textos se les asignó un 7; otros 10 fueron calificados con un 8; siete trabajos obtuvieron un 9; y solo a tres se les asignó un 10. En siete de los textos que fueron calificados con las notas más altas (9 y 10), la docente incluyó elogios. En la siguiente imagen se muestra un ejemplo de un texto al que se le asignó la nota numérica más alta y el elogio añadido ("Te felicito, entrelazaste varias acciones").

Imagen 8. Ejemplo de comentarios a trabajos calificados con notas numéricas altas

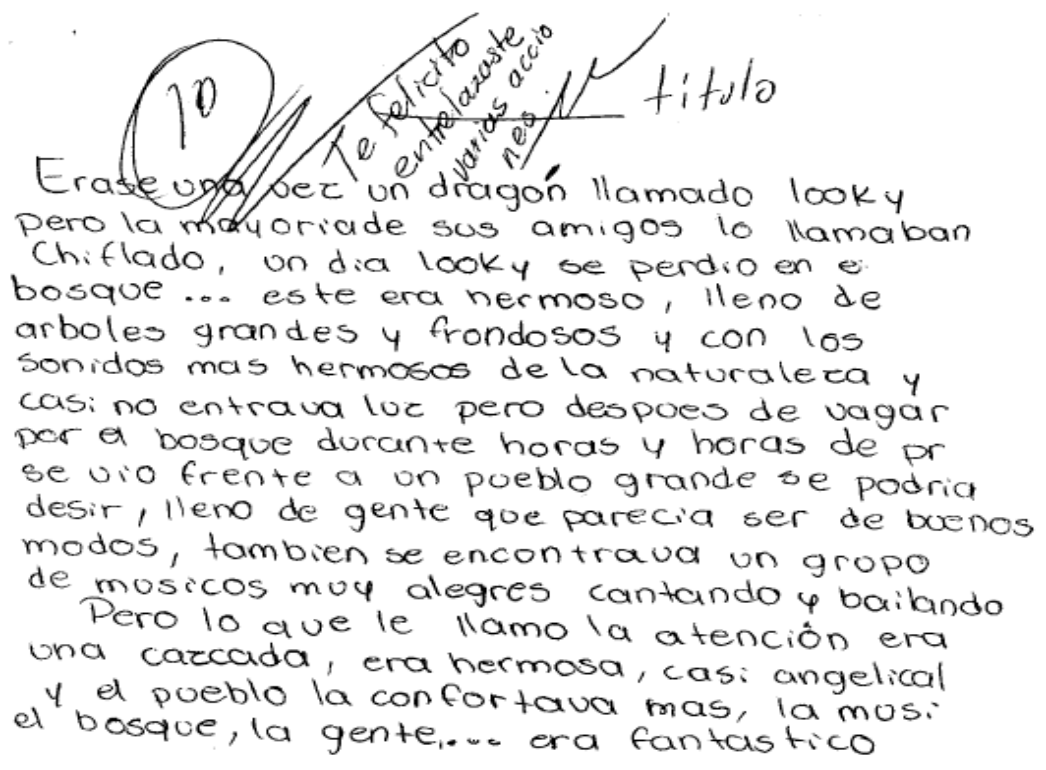

En cuatro de los 10 trabajos con las calificaciones más altas se encontraron notas escritas que enfatizan aquello que no hicieron los estudiantes, por ejemplo: "En momentos perdiste la coherencia de la trama. Pero te felicito". El comentario señala una limitación, aunque de forma imprecisa, no hay un señalamiento de la manera en que la coherencia no estuvo presente. En 
seis de los textos que obtuvieron un 8 también se encontraron comentarios de este tipo, sin embargo, en este grupo de trabajos se detectaron dos que contenían notas escritas con potencial de orientar a los alumnos a la mejora, por ejemplo: “Debes usar sinónimos y así no repites la palabra". En los 11 trabajos con las calificaciones más bajas (6 y 7), únicamente se incluyeron comentarios que señalan los errores de los estudiantes. En la siguiente imagen se observa que la docente apunta que en la narración "faltó más creatividad" y no había "conflicto". Estos comentarios no dan información que pueda retomar el alumno para su mejora, por ejemplo, la manera en la que se podría haber construido un conflicto o la forma en que se manifiesta la creatividad en el texto.

Imagen 9. Ejemplo de comentarios a trabajos calificados con notas numéricas bajas

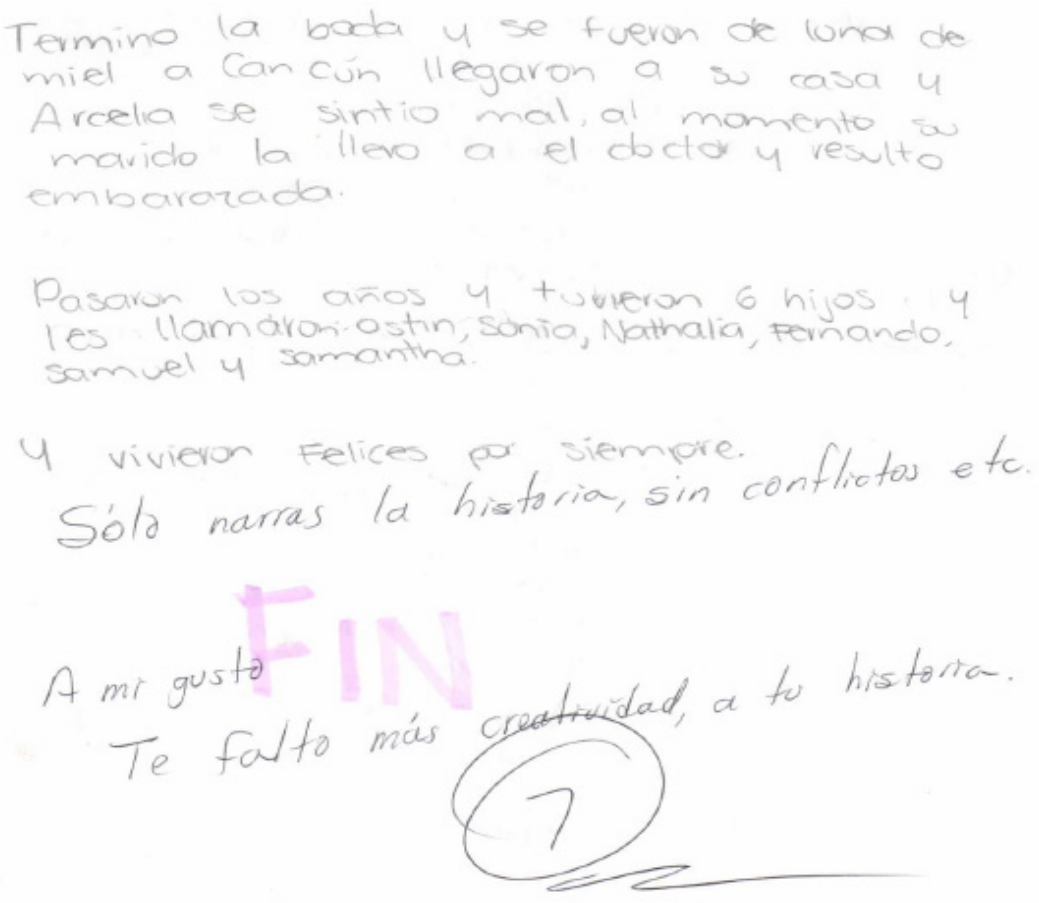

Durante el desarrollo del proyecto didáctico en el que se produjeron los textos analizados, la docente no estableció criterios específicos para la asignación de calificaciones. El uso de las calificaciones como recurso principal para proveer retroalimentación a los alumnos, y la falta de criterios en su asignación, son prácticas comunes y representan un problema en tanto que no brindan información suficiente a los estudiantes para mejorar (Elliot et al., 2016).

Las limitaciones de las calificaciones para retroalimentar el desempeño de los alumnos están documentadas en la literatura. Ravela (2009), y García et al. $(2011,2015)$ sostienen que las calificaciones no brindan suficiente información a los estudiantes acerca de lo que necesitan

Diálopos sobre Educación año 12 | número 23 | julio-diciembre 2021 | ISSN 2007-2171 
para avanzar en su aprendizaje, ya que no se basan en objetivos o referentes de aprendizaje definidos con claridad (Ravela, 2009) y, debido a que proporcionan una visión global del nivel de calidad del trabajo, no permiten que los alumnos identifiquen sus fortalezas y debilidades, por ende, no se constituyen como una retroalimentación descriptiva (García et al. 2011).

\section{¿Cómo interpretan los estudiantes la retroalimentación que se proporcionó a sus trabajos escritos?}

En las entrevistas aplicadas a los tres alumnos seleccionados (Sofía, Emiliano y Catalina) se indagó sobre sus interpretaciones en torno a los diferentes recursos que la profesora empleó para retroalimentar sus textos: 1) calificaciones; 2) comentarios escritos; y 3) marcas gráficas.

Con respecto a las calificaciones, Sofía, cuyo trabajo obtuvo un 6, atribuyó su nota numérica "...[a] las faltas de ortografía". El significado que la alumna da a la calificación podría dar una pista para el futuro (i.e. revisar la ortografía de los trabajos antes de entregarlos), pero no muestra lo que logró con respecto a los aprendizajes esperados. Por ejemplo, la retroalimentación no le permite saber en qué medida consiguió modificar la estructura del cuento e ilustrar las implicaciones de estos cambios. Este tipo de retroalimentación puede afectar negativamente a los estudiantes. En este caso, Sofía señaló: "Sí me hace [sentir] mal, pero, ¿qué puedo hacer? [...], ya está la calificación, ya no la voy a poder cambiar, con esa se va a quedar; sí me siento mal y todo, pero ni modo, ya la tengo". La respuesta de la estudiante manifiesta un impacto negativo y revela también que la retroalimentación no es vista como una vía para modificar su trabajo, además de ser un proceso en el que no puede intervenir, pues apunta que la calificación se mantendrá así y que no puede hacer nada al respecto.

Emiliano, a quien la docente asignó un 8 como nota numérica, señaló que esta significaba "que lo hice bien y puedo mejorar", pero no mencionó lo que había logrado, lo que le faltaba y cómo podría mejorar. También se entrevistó a Catalina, que obtuvo la nota numérica más alta (10), para ella esta calificación indicaba que: "A lo mejor a la maestra le parecieron muy buena idea las transformaciones que hice [...]".

Como se puede apreciar, las interpretaciones de los alumnos sobre las calificaciones son generales, es decir, a partir de las notas numéricas que recibieron en sus textos escritos no pudieron identificar de forma específica qué deberían mejorar en relación con su desempeño en su trabajo o las estrategias que podrían emplear para lograrlo. Esto sugiere una carencia de referentes claros acerca de la asignación de calificaciones y hace que la retroalimentación sea genérica o imprecisa, y, por lo tanto, poco efectiva para promover el aprendizaje de los alumnos (Elliot et al., 2016).

En las entrevistas también se cuestionó a los estudiantes sobre los significados atribuidos a los comentarios escritos. En el texto de Sofía, su profesora indicó: "Te faltó coherencia, no se entiende tu trama. La ortografía, no la checaste" (imagen 4), comentario que la alumna explicó con las siguientes palabras: 
Pues que le faltó más... como trama, así más... o sea, ir así de partes en partes con más emoción sobre mi cuento, yo así lo creo [...] y de la ortografía, pues igual como dice ahí, pues igual no la chequé, porque sí tengo muchas... faltas de ortografía.

En el trabajo de Emiliano se encontró la siguiente nota:"Te faltó explicar algunas acciones con más claridad". El estudiante indicó que su docente, a través de este comentario, indicaba que debía "explicar los personajes, describir a los personajes". En el texto de Catalina la docente anotó:"Buena transformación de la historia real", en la entrevista, la alumna no hizo comentarios al respecto.

Las interpretaciones que hicieron los alumnos a partir de los comentarios escritos conllevan una carencia de claridad con respecto a los objetivos de aprendizaje y los criterios de éxito de la consigna, y permiten ver problemas de comprensión acerca de algunos de los conceptos que fueron parte del proyecto didáctico (e.g. acciones, coherencia, trama), lo que tal vez derive en que los estudiantes no mejoren su desempeño de la manera en que la docente lo tenía previsto.

A propósito de las marcas gráficas que la docente utilizó para retroalimentar los textos escritos, los alumnos entrevistados mostraron tener una comprensión clara acerca del significado de algunas de estas; los tres coincidieron en que las palabras encerradas en un círculo señalan faltas ortográficas y Emiliano indicó que el subrayado hacía referencia a una repetición. Aunque los estudiantes reconocieron la orientación de estos señalamientos, se desconoce si identifican con precisión la naturaleza de los errores que marcó su profesora, así como las estrategias para corregirlos. Es importante mencionar que durante la entrevista, los alumnos señalaron que una vez que la docente entregó su trabajo con la retroalimentación, ellos no hicieron ningún tipo de modificación a los textos.

\section{¿Qué correspondencia guarda la retroalimentación brindada con los criterios de retroalimentación efectiva derivados de la literatura?}

Las evidencias recopiladas fueron analizadas en función de los seis rasgos que, de acuerdo con la literatura científica, caracterizan a la retroalimentación efectiva. Los rasgos que fueron listados en el apartado de análisis, dentro de la sección metodológica de este documento, tienen que ver con: la correspondencia de la retroalimentación con los objetivos de aprendizaje; el contraste que ofrece la retroalimentación entre el desempeño actual de los estudiantes y el logro de aprendizaje deseable; el nivel de descripción de la retroalimentación; la promoción de la corrección de errores y búsqueda de soluciones por los estudiantes mismos; el grado de especificidad y precisión de la retroalimentación; y su focalización en el proceso o en el producto de la escritura.

Se encontró que gran parte de la retroalimentación que la docente hizo al trabajo de los alumnos no tiene correspondencia con los objetivos de aprendizaje, ni con los criterios de éxito de la consigna o las características de un trabajo de calidad. Asimismo, se observó que, aunque 
los aprendizajes esperados del proyecto didáctico se compartieron en el aula, no fueron retomados en la retroalimentación que hizo la profesora, por lo que los estudiantes no contaron con información que les permitiera saber en qué medida los alcanzaron.

Aunque entre los comentarios escritos se identificaron algunos que ofrecen orientaciones o vías de mejora, en ninguno de los textos analizados la retroalimentación brindó a los estudiantes un contraste entre su desempeño actual y el deseable, ni estrategias que, en función de esta información, les ayudara a cerrar la brecha entre lo real y lo esperado.

Algunas de las limitaciones que se detectaron en la retroalimentación a los textos escritos, tal vez podrían atribuirse a fenómenos detectados con anterioridad en la literatura científica (Moats, Lyon, 1996; Kluger, DeNisi, 1998; Hyland, 2000; Moats, 2000; Municie, 2000; Wong-Fillimore, Snow, 2002, en Parr, Timplerley, 2010), tales como el que la docente tuviera poco dominio de los conocimientos relacionados con el sistema de escritura o que haya enfrentado dificultades para establecer lo que involucra un desempeño esperado en esta área del conocimiento. Cabe recordar que la profesora no estableció criterios de éxito para los aprendizajes esperados de la consigna.

También se encontraron algunas dificultades señaladas previamente en otros estudios (Parr, Timperley, 2010), como la tendencia de los docentes a enfocarse en las cualidades personales de los estudiantes, en lugar de hacer referencia a las características de su trabajo o su desempeño en la consigna, lo que se constató en los diversos elogios que fueron observados en los textos escritos. Asimismo, diversos autores (Picaroni, 2009; Parr, Timperley, 2010; García et al., 2011; Elliot et al., 2016) indican que los profesores, a través de la retroalimentación, no brindan suficiente información a los estudiantes para mejorar. Esto se identificó en gran parte de los trabajos de los alumnos, pues los comentarios se centraron principalmente en aquello que no lograron en la realización de la consigna; algunas notas escritas se concentraron en aspectos demasiado generales, otras no permitían identificar en dónde se encontraban las áreas de oportunidad o su significado era ambiguo.

La mayor parte de la retroalimentación se focalizó en el producto, es decir, en los textos escritos, y únicamente se identificó un comentario escrito relacionado con el proceso de escritura: "Recuerda que en el borrador se hacen las correcciones". Más allá del comentario en sí mismo, no hay indicios en el texto que permitan inferir el sentido de esta nota, ya que ni la docente ni el estudiante hicieron anotaciones o marcas adicionales acerca de este tema. Durante el desarrollo del proyecto didáctico en el aula no se observó que la profesora hiciera señalamientos acerca del proceso de escritura.

De acuerdo con el análisis realizado, la retroalimentación también pudo haber tenido un potencial limitado para promover la corrección de errores y la búsqueda de soluciones por parte de los alumnos, debido a que las calificaciones, los comentarios escritos y las marcas gráficas brindan pocas pistas a los estudiantes para detectar lo que deben mejorar y les proporcionan 
escasas estrategias para llevarlo a cabo. Además de que, como se indicó en el apartado anterior, ninguno de los alumnos hizo correcciones a su trabajo una vez que estos fueron entregados por la docente.

\section{Discusión y conclusiones}

Los resultados de la investigación presentada muestran que las calificaciones, comentarios escritos y marcas gráficas fueron recursos empleados para proveer retroalimentación a los alumnos. También se encontró que en la mayoría de los trabajos escritos se incluyó al menos uno de estos recursos, evidenciando que todos los trabajos de los alumnos fueron revisados por la docente y recibieron retroalimentación. Si bien este resultado es alentador, pues en la literatura se ha encontrado que recibir algún tipo de retroalimentación es mejor que la ausencia de esta (Butler, Nisan, 1986; Koenka et al., 2019), el análisis de las características de los recursos empleados mostró que podrían tener un potencial limitado para promover la mejora del aprendizaje de los estudiantes.

Una de las limitaciones principales encontradas es que la retroalimentación a través de los tres recursos, no tuvo como referente los aprendizajes esperados planteados en el currículo para el proyecto didáctico seleccionado. Esta limitación es importante, porque la referencia a los aprendizajes esperados constituye el punto de partida para que los estudiantes puedan identificar la cercanía de lo que produjeron con respecto a lo que se esperaba que aprendieran , y posteriormente puedan implementar estrategias para cerrar la brecha.

Otro hallazgo de esta investigación es que la retroalimentación brindada ofrece escasas orientaciones para la mejora de los desempeños futuros de los alumnos. Se reconoce que en este estudio se emplearon los productos finales entregados por los alumnos $y$, en principio, esto supondría que no requieren realizar correcciones para mejorarlos; sin embargo, algunos autores apuntan que cuando los docentes identifican correcciones por realizar en la mayoría de los productos finales, pueden optar por solicitar una entrega posterior en donde las correcciones se hayan realizado (Chappuis et al., 2014); además, dado que los productos fueron entregados en el segundo bloque del ciclo escolar, se esperaría que la retroalimentación proporcionara elementos que los estudiantes pudieran incorporar en los tres bloques restantes. En el análisis de la retroalimentación se encontró que la mayoría de los comentarios escritos se focalizaron en los fallos de los productos, sin proporcionar pistas para realizar modificaciones. Esto sobresale porque se espera que la retroalimentación promueva la capacidad de los alumnos para tomar decisiones que les permitan alcanzar los aprendizajes esperados del bloque curricular en cuestión o de unidades de aprendizaje futuras, y que contribuyan a su autonomía en la regulación de los procesos de aprendizaje. Sin orientaciones, se afecta la capacidad de acción de los estudiantes, y es probable que en productos realizados en bloques posteriores se repitan los fallos y los alumnos se mantengan sin conocer de qué manera mejorar su desempeño. Así, la retroalimentación no parece ser efectiva.

Diálopos 
Las limitaciones mencionadas previamente han sido documentadas en la literatura (cfr. Parr, Timperley, 2010; Elliot et al., 2016). Autores como Chappuis et al. (2014) han trabajado en el fortalecimiento de las competencias docentes para examinar los planteamientos curriculares, pues reconocen que entender los objetivos de aprendizaje establecidos en el currículo y cómo convertirlos en criterios de desempeño comunicables, para los estudiantes es un gran desafío. Este desafío muestra que las prácticas de retroalimentación de los docentes pueden ser influenciadas por la manera en que se estructura y especifica el currículo, y revela oportunidades para el diseño curricular y las ofertas formativas para los docentes. Por ejemplo, en los planteamientos curriculares podrían incluirse criterios para identificar el logro de los objetivos de aprendizaje, de tal modo que sirvan como guía para los docentes. Además, podrían desarrollarse ofertas formativas que fomenten el análisis del currículo, la identificación y establecimiento de criterios de logro de los objetivos de aprendizaje, el diseño de actividades basadas en los criterios de logro, y la orientación de los alumnos para alcanzarlos.

El análisis presentado permite argumentar que el registro de calificaciones, comentarios o marcas gráficas, aun cumpliendo las características de la retroalimentación efectiva, podrían ser insuficiente si no se provee de manera oportuna y no se acompaña de espacios específicos para que los alumnos los revisen, discutan con el docente sobre su significado y sin la oportunidad para corregirlos. Las evidencias recuperadas en esta investigación sugieren que los estudiantes no ven la retroalimentación como un proceso en el que puedan participar, examinando con su profesora las observaciones y precisando sus implicaciones. La participación de los estudiantes en la retroalimentación es una condición relevante para promover un cambio en el aprendizaje.

Esta investigación se centró en la retroalimentación escrita a las producciones de los alumnos, aunque los docentes pueden proveer retroalimentación también a través de la comunicación oral. Convendría que estudios futuros analicen la provisión de retroalimentación a productos escritos a través de ambos medios, para contribuir a una comprensión integral de este proceso. En otras publicaciones relacionadas con este proyecto de investigación se pretende abonar en esta línea, haciendo uso de la información recuperada a través de la observación en aula y analizando otros insumos de las entrevistas realizadas a la docente y los alumnos.

Investigaciones futuras podrían también explorar qué influencia las prácticas de retroalimentación de los docentes. Las prácticas pueden ser influenciadas por características personales del docente, relacionadas con su formación inicial o en servicio, sus creencias sobre la evaluación de aprendizajes, y las experiencias previas que haya tenido en su labor docente, entre otras; también podrían ser influenciadas por los planteamientos curriculares, como se mencionó antes, y los materiales que se proveen para la práctica (v.gr. libros de texto). Además, la literatura sobre retroalimentación y la revisión de trabajos escritos muestra que lo que hacen los docentes se delimita por decisiones escolares. Como comunidad, las escuelas determinan comportamientos de revisión y retroalimentación: qué retroalimentar, con qué frecuencia, 
cómo proveer la retroalimentación. Es necesario que la relación entre la retroalimentación, las decisiones escolares y otros factores que influencian las prácticas sean objeto de investigación, pues permitirá identificar posibilidades para transformarlas.

Otro aspecto que parece necesario se profundice en investigaciones futuras, es el enfoque de la retroalimentación de la escritura, en particular, el tipo de retroalimentación que se brinda sobre el proceso de escritura y el producto. Este estudio estuvo concentrado en las producciones finales de los estudiantes, sin embargo, el proceso de la escritura también podría haber sido objeto de retroalimentación, y la contribución de las orientaciones sobre este proceso son fundamentales para la formación de los estudiantes.

Continuar investigaciones como la aquí expuesta es importante, debido a que la retroalimentación a la escritura brinda a los alumnos la posibilidad de mejorar su proceso de escritura y sus textos, otorgándoles así mayores oportunidades de incorporarse a la cultura escrita de manera exitosa y permitiéndoles consolidar la gestión de su aprendizaje.

\section{Referencias}

Black, P.; C. Harrison; C. Lee; B. Marshall; D. Wiliam (2003). Assessment for Learning. Putting it into Practice. Nueva York: Open University Press.

Black, P.; D. Wiliam (1998). Assessment and Classroom Learning. Assessment in Education, 5(1), 7-73.

Black, P.; D. Wiliam (2010). Inside the Black Box: Raising Standards Through Classroom Assessment. Phi Delta Kappan, 92(1), 81-90.

Brookhart, S. M. (2017). How to Give Effective Feedback to Your Students ( $2^{\mathrm{a}}$ ed.). ASCD.

Brookhart, S. M.; J. H. McMillan (2020). Introduction. En Brookhart S. M.; J. H. McMillan (eds.). Classroom Assessment and Educational Measurement. Routledge, 1-7.

Brooks, C.; A. Carroll; R. Gillies; J. Hattie (2019). A Matrix of Feedback. Australian Journal of Teacher Education, 44(4), 14-32. https://doi.org/10.14221/ajte.2018v44n4.2

Bruno, l.; L. Santos (2010). Written Comments as a Form of Feedback. Studies in Educational Evaluation, 36(3), 111-120.

Butler, R.; M. Nisan (1986). Effects of No Feedback, Task-Related Comments, and Grades on Intrinsic Motivation and Performance. Journal of Educational Psychology, 78(3), 210-216.

Castelló, M. (2002). De la investigación sobre el proceso de composición a la enseñanza de la escritura. Revista Signos, 35(51-52), 149-162.

https://scielo.conicyt.cl/scielo.php?script=sci arttext\&pid=S0718-09342002005100011

Chappuis, J.; R. Stiggins; S. Chappuis; J. Arter (2014). Classroom Assessment for Student Learning. Pearson Education Limited.

Creswell, J. W.; C. N. Poth (2018). Qualitative Inquiry Research Design. Choosing Among Five Approaches. Thousand Oaks: Sage Publications. 
Elliot, V.; J. A. Baird; T. N. Hopfenbeck; J. Ingram; I. Thompson; N. Usher; M. Zantout (2016). A Marked Improvement? A Review of the Evidence on Written Karking, Londres: University of Oxford-Education Edowment Foundation.

Flick, U. (2004). Introducción a la investigación cualitativa. Madrid: Morata.

García, A. M.; M. A. Aguilera; M. G. Pérez; G. Muñoz (2011). Evaluación de los aprendizajes en el aula. Opiniones y prácticas de docentes de primaria en México. México: Instituto Nacional para la Evaluación de la Educación. https://www.inee.edu.mx/wp-content/uploads/2019/01/P1D410.pdf

García, A. M.; M. G. Pérez; R. A. Sepúlveda; L. Y. Rodríguez; A. Mercado (2015). Herramientas para mejorar las prácticas de evaluación formativa en la asignatura de Español. México: Instituto Nacional para la Evaluación de la Educación.

Goh, K. P. T. (2019). Written Feedback: Exploring the Reflections of Upper Primary Music Students at Two Western Australian Schools. PhD Thesis. Curtin University.

Hattie, J.; H. S.; Timperley (2007). The Power of Feedback. Review of Educational Research, 77(1), 81-112.

Hounsell, D.; V. McCune; J. Hounsell; J. Litjens (2008). The Quality of Guidance and Feedback to Students. Higher Education Research \& Development, 27(1), 55-67.

Koenka, A. C.; L. Linnenbrink-García; H. Moshontz; K. M. Atkinson; C. E. Sánchez; H. Cooper (2019). A Meta-Analysis on the Impact of Grades and Comments on Academic Motivation and Achievement: A Case for Written Feedback. Educational Psychology, 1-22. https://doi.org/10.1080/01443410.2019.1659939

Lerner, D; A. Larramendy; K. Benchimol (2010). Tensiones de la escritura en el contexto escolar. Análisis desde una investigación sobre la enseñanza y el aprendizaje de contenidos histórico. En Vázquez A.; M. Novo; I. Jakob; L. Pelliza (Comps.). Lectura, escritura y aprendizaje disciplinar. Río Cuarto, Córdoba, Argentina: Universidad Nacional de Río Cuarto, 41-86.

Lipnevich, A. A.; J. K. Smith (2009). Effects of Differential Feedback on Students' Examination Performance. Journal of Experimental Psychology:Applied, 15(4), 319-333. https://doi.org/10.1037/a0017841

Oxford University Press (2020). Oxford Learner's Dictionaries. https://www.oxfordlearnersdictionaries.com/us/definition/english/marking?q=marking

Parr, J. M.; H. S. Timperley (2010). Feedback to Writing, Assessment for Teaching and Learning and Student Progress. Teaching and Teacher Education, 15(2), 68-85.

Picaroni, B. (2009). La evaluación en las aulas de primaria: usos formativos, calificación y comunicaciones con los padres. http://www.preal.org/Archivos/Grupos de Trabajo/Evaluación y Estándares/Publicaciones/evaluacion aula Picaroni1(1).pdf

Ravela, P. (2009). Consignas. Devoluciones y calificaciones. Problemas de la evaluación en aulas de educación primaria en América Latina. Páginas de Educación, 2(1), 49-89.

Ravela, P.; B. Picaroni; G. Loureiro (2017). ¿Cómo mejorar la evaluación en el aula? Reflexiones y propuestas de trabajo para docentes. Montevideo: Grupo Magro Editores. 
Riesco, A. (2002). Función social de la escritura. Revista General de Información y Documentación, 12(2), 393-428.

Rovira, C. (2004). Fundamentos de la investigación en ciencias sociales y humanidades: el estudio de caso. En Codina, L.; M. Marcos; M. Palma; C. Rovira. Información y documentación digital. Barcelona: Ediciones Petició, 11-40.

Ruiz-Primo, M. A.; S. M. Brookhart (2018). Using Feedback to Improve Learning. Routledge.

Secretaría de Educación Pública (2011). Programas de Estudio 2011. Guía para el maestro. Educación Básica. Secundaria. Español. México: SEP.

Shute, V. J. (2008). Focus on Formative Feedback. Review of Educational Research, 78(1), 153-189. https://doi.org/10.3102/0034654307313795

Sommers, N. (1982). Responding to Student Writing. College Composition and Communication, 33(2), 148-156.

Timperley, H. (2013). Feedback. En Hattie J.; E. Anderman (eds.). International Guide to Student Achievement. Routledge, 402-404.

UNESCO (2015). Declaración de Incheon Educación 2030: Hacia una educación inclusiva y equitativa de calidad y un aprendizaje a lo largo de la vida para todos. http://unesdoc.unesco.org/images/0024/002456/245656s.pdf

Wiggins, G. (1998). Educative Assessment. Designing Assessments to Inform and Improve Student Performance. San Francisco: Jossey-Bass. 